(C) The Author(s), 2021. Published by Cambridge University Press. This is an Open Access article, distributed under the terms of the Creative Commons Attribution licence (https://creativecommons.org/licenses/by/4.0/), which permits unrestricted re-use, distribution, and reproduction in any medium, provided the original work is properly cited. doi:10.1017/S1474746421000555

\title{
The Social Practices of Food Bank Volunteer Work
}

\section{Richard Philip Lee* (D), Caroline Coulson** and Kate Hackett***}

*Faculty of Health and Life Sciences, Northumbria University, Newcastle upon Tyne, UK.

E-mail: richard.p.lee@northumbria.ac.uk

**NHS Health Call, Gateshead, Tyne and Wear, UK.

E-mail: caroline.a.coulson@outlook.com

***Faculty of Health and Life Sciences, Northumbria University, Newcastle upon Tyne, UK.

E-mail: kate.hackett@northumbria.ac.uk

The on-going rise in demand experienced by voluntary and community organisations (VCOs) providing emergency food aid has been described as a sign of a social and public health crisis in the UK (Loopstra, 2018; Lambie-Mumford, 2019), compounded since 2020 by the impact of (and responses to) Covid 19 (Power et al., 2020). In this article we adopted a social practice approach to understanding the work of food bank volunteering. We identify how 'helping others', 'deploying coping strategies' and 'creating atmospheres' are key specific (and connected) forms of shared social practice. Further, these practices are sometimes suffused by faith-based practice. The analysis offers insights into how such spaces of care and encounter (Williams et al., 2016; Cloke et al., 2017) function, considers the implications for these distinctive organisational forms (the growth of which has been subject to justified critique) and suggests avenues for future research.

Keywords: Social practice, food banks, volunteering, faith, qualitative.

\section{Introduction}

The on-going rise in demand experienced by voluntary and community organisations (VCOs) providing emergency food aid (including food banking) has been described as a sign of a possible social and public health crisis in the UK (Loopstra, 2018; LambieMumford, 2019), compounded since 2020 by the impact of (and responses to) Covid 19 (Power et al., 2020). There has been a growing (critical) analysis of this situation. According to Williams et al. (2016), four critical narratives of food banking have emerged: food banking depoliticises food insecurity issues; it enables the state to retreat; it contributes to the subjectification of 'the poor'; the charitable ethos assuages guilt rather than prompting active engagement. Taking each in turn, it has been suggested that food banking is representative of the 'depoliticalisation' of food poverty through the ubiquity of charitable institutions (Dowler and Lambie-Mumford, 2015). The retreatment of the state (local, regional, nation) - in the UK significantly hastened by the implementation of austerity measures from 2010 onwards - has also been cited as a driver of shifting responsibility for addressing issues of poverty to VCOs (Caplan, 2016; Garthwaite, 2017; Lambie-Mumford, 2019; MacLeod et al., 2019). The creation of places of 'neediness' and the use of voucher systems - has led to criticisms of food banking as contributing to the stigmatisation of people living in poverty (Carson, 2014) through an active production 
of scarcity (May et al., 2019). Food banking has also been critiqued as having a placatory (and even celebratory) impact on volunteers and wider publics (Poppendieck, 1998; Strong, 2021). The argument of Williams et al. (2016) is that while all these perspectives are important and valuable, they may miss (or downplay) opportunities. In particular, Williams et al. (2016) consider food banks as possible 'spaces of encounter' (albeit existing within a highly problematic 'meantime', or 'realism'; see Fisher (2009) on 'capitalist realism'), with potential for generating new relationships and enabling dialogue between people with different experiences, backgrounds, incomes, cultures, resources and values.

Based on our analysis of interviews with volunteers, in this article we consider the key social practices which comprise the work of food bank volunteering: helping others, deploying coping strategies, creating atmospheres. Volunteers play a crucial role in the operation of food banking. Along with tasks such as unloading and sorting food and other items (such as toys) and making up food parcels, volunteers work to produce spaces of encounter and care (Cloke et al., 2017). In studies of volunteer work, associations have been proposed between volunteering and enhanced purpose of life (Son and Wilson, 2012) and feeling less hopeless (Gilster, 2012). It has been suggested that volunteering could function as an effective intervention for those suffering role and spouse loss in older age (Jenkinson et al., 2013; Jang et al., 2018) and could improve functional and cognitive abilities (Okun et al., 2010; Chiao, 2018). However, stress and burnout can affect volunteers (Roche and Ogden, 2016) and the Trussell Trust (the largest food bank organisation in the UK) has reported concerns regarding the health and wellbeing of their volunteers as demand increases (The Trussell Trust, 2017).

The initial focus of our study (in terms of research aims, questions and interview topic guides) was on exploring the wellbeing practices of volunteers. In doing so we drew on notions of wellbeing as being situated, emergent and contingent (Sointu, 2005; Deci and Ryan, 2008; Carlisle et al., 2009; White, 2017; Smith and Reid, 2018). However, guided by the data, interpretations and critiques of food banking, our analysis focused less on the concept of situated wellbeing, and more on the social practices that comprised the work of food bank volunteering ${ }^{1}$. In particular, we recognised that three key social practices ('helping others', 'deploying coping strategies' and 'creating atmospheres') were sometimes 'suffused' (a conceptual term discussed later in the article) by faith-based practices. In the following section we describe in more detail social practice approaches.

\section{Social practice approaches}

Our initial focus on situated wellbeing bore some resemblance to the analysis of Armour and Barton (2019), who consider some of the key elements of psychological wellbeing relevant to people volunteering in food banks. In particular, their focus on the importance of 'relatedness' resonates with situated wellbeing. A relational approach ensures that individuals are not conceptualised and investigated as self-contained entities. Baylis et al. (2008) terms this 'relational personhood' and draws attention to the centrality of relationships and social connections to the constitution of an individual. However, our engagement with the data suggested that social practices (rather than wellbeing directly) should be the focus of analytical interpretation.

Social practice approaches give primacy to shared, routinised forms of behaviour (Reckwitz, 2002). Practices are repetitious ways of doing, incorporating talk, bodies, 
minds, knowledge and things. Schatzki (2001: 48) regards a practice as a 'set of actions', with each action being constituted by 'doings and sayings'. Similarly, Reckwitz (2002) identifies a practice as a discernable 'type' of behaving and understanding. Further, Schatzki (2005) contends that an organisation is a mesh (or nexus) of practice-arrangement bundles and that these bundles (arising from local actions and tasks) are constitutive of social formations.

A social practice approach has been theorised, developed and deployed to understand a range of social policy, public health and organisational issues (Milne, 2011; Nicolini, 2012; Shove et al., 2012; Watson, 2013; Meah, 2014; Maller, 2015; Blue et al., 2016; Hui et al., 2017). All draw attention to the performance of practices (through doings and sayings) by people who are recruited into the practice; as Blue et al. (2016) emphasise the focus is upon how participation in a practice is sustained (and that commitment arises through engagement, rather than an individualised pre-condition for ongoing participation). This is not to say that people do not have reasons for becoming involved in a practice-arrangement bundle (an organisation), but that these reasons become integrated as one of several actions which will make up practices and their continued performance. Shove et al. (2012) and Maller (2015) emphasise the importance of meanings (conventions, expectations, intentions and shared meanings), materials (objects, tools, infrastructures) and competencies (knowledge and embodied 'know-how') to the ongoing performance of social practices. Further, Reckwitz (2012) elaborates on the importance of emotions, senses and spaces to social practices, emphasising that every social practice forms senses and perceptions in particular ways.

In order to understand the work of food bank volunteering, a social practice approach suggests attention should be paid to the shared, routinized actions and tasks performed and to consider how they are made coherent, how practices compete or are compatible and the senses and perceptions they produce.

\section{Methods}

Semi-structured interviews were conducted June - July 2018 by CC with thirteen volunteers (also referred to as participants) from three food banks (referred to as Red; Blue; and Green) in a large city in the North of England (see Table 1 for participant details). All interviews were conducted at these sites, along with informal observations and conversations. Interviews and focus groups are valid methods when adopting a social practice perspective (Milne, 2011; Hitchings, 2012). In particular, Hitchings (2012) argues that talk is an appropriate means of understanding practices and that semi-structured interviews can play an important role in producing accounts of shared, routinised activities. Keane et al. (2017) and Milne (2011) make use (respectively) of surveys to understand vaping practices and focus groups to understand food storage practices, demonstrating that reported action can be an important means by which to examine social practices. The importance of language in social practice is also recognised by Schatzki (2017) in his discussion of the 'sayings and doings' that form practice arrangements bundles.

All except two of the thirteen participants were retired and only one participant was male. The selection of the city was guided by practical constraints (time and funding), but we sought to draw upon diverse sites. The Red and Blue sites were both operated by the Trussell Trust. The Red site was a solitary building in a small area of grounds. It had a room 
Table 1 Participants

\begin{tabular}{llll}
\hline \hline No. & Demographic details & Work status & $\begin{array}{l}\text { Express a faith } \\
\text { (Christian) }\end{array}$ \\
\hline 01 & White British, female, 50+ & Not working due to ill health & No \\
02 & N/A (see explanation in Methods) & N/A & N/A \\
03 & White British, female, 50+ & Retired & Yes \\
04 & White British, female, 50+ & Retired & Yes \\
05 & White British, female, 50+ & Retired & Yes \\
06 & White British, female, 50+ & Retired & Yes \\
07 & White British, female, 50+ & Retired & Yes \\
08 & White British, female, 50+ & Retired & Yes \\
09 & White British, male, 50+ & Retired & Yes \\
10 & White British, female, 50+ & Retired & Yes \\
11 & White British, female, 18-25 & Work experience before & No \\
& & University study & No \\
12 & White British, female, 50+ & Retired & No \\
13 & White British, female, 30-40 & Not working due to ill health & No \\
14 & White British, female, 50+ & Retired & No \\
\hline \hline
\end{tabular}

that functioned as an office, a store cupboard, a room used largely for storage and a kitchen that opened onto a comparatively large space used for dining. The Blue site operated out of a church. Here food parcels were kept and clients would come in, hand over their voucher and collect their food. To the rear was a small open kitchen where beverages were prepared and an adjacent room where clients could talk to volunteers. The Green site also operated out of a church, this time in a town centre, but the available space for the volunteers to perform their tasks was far greater than at the Blue site and included at least four large multi-purpose rooms, a large kitchen and the manager's office/ store cupboard.

Participants in all three sites were approached directly by CC after gaining access through gatekeepers (in all cases, the most senior site manager). The transcript from an interview with Participant 2 was disregarded due to a subsequent age disclosure. As stated above, Red and Blue were Trussell Trust sites and an invitation to visit the Blue site was only received after visiting the Red site. All but one of the participants were female. A key characteristic (discussed in more detail in the Results section) was involvement in organised religion (Christianity). Participants 3, 4, 6-10 all described their involvement with organised religion and the implications for practice. Participants 1, 11-14 did not express any involvement with organised religion (see table).

Ethical approval for the research was obtained from Northumbria University Health and Life Sciences Ethics Committee in June 2018. Semi-structured interviews were conducted based on a topic guide featuring the following questions:

- Can you tell me about the food bank you work in and what you do there?

- How would you currently describe your health?

- Can you tell me about any experiences you have had at the food bank that you feel are relevant to your health? 
- Can you tell me about any situations at the food bank where you have experienced strong or surprising emotions?

- How would you currently describe your emotional wellbeing?

- Are there any interactions with those you work with or with people who use the food bank that you would like to tell me about?

The interviews were audio recorded and transcribed verbatim by CC. All names of participants and identifying details were anonymised. Data analysis was conducted by CC and RPL drawing upon an iterative process of thematic analysis (Braun and Clarke, 2006). A series of analysis meetings were used to develop the data-driven open coding, drawing on the interview data and upon field notes from informal conversations and observations. Twelve initial themes were developed and refined through thematic mapping and referenced back to initial quotes to ensure reliability (Silverman, 2014). Thematic saturation was identified (Saunders et al., 2018) and issues pertaining to this are discussed further in the Discussion and Conclusion sections.

\section{Faith, practice and 'suffusion'}

From a social practice perspective, certain identifiable objects or practices can 'thread through' a nexus of practices, while other more diffuse socio-material arrangements can 'suffuse' practices (Hui et al., 2017). Threading and suffusion are important (though nascent) theoretical categories in social practice approaches, the former involving the 'concrete' and the latter the 'ethereal'. Through our analysis it became apparent that faith practices suffuse other practices: for example, 'acting as a Christian' comprising one action/element of the practice 'helping others' (see the following section and Table 2 for further discussion of this). While the research design was not primarily focused on the relevancy of religion, we expected (owing to the nature of the research sites and the broader organisation of food banking) that religion would have an influence on the practices of participants. Eight participants expressed an adherence to Christian beliefs and/ or stated that they attended church. Although not all volunteers practiced a faith, group prayer took place at Red and Blue food banks (as also described by Garthwaite, 2016).

It has been recognised that organised religion often acts as a gateway to volunteering (Wilson and Janoski, 1995; Mencken and Fitz, 2013; Lim and MacGregor, 2014), while Cloke and Beaumont (2013) have considered the emergence of 'postsecular' urban spaces, with renewed faith-based practical action taking place in partnership with secular individuals and groups. More specifically, religious organisations have been heavily involved in the (growing) organisation and management of food banks (exemplified by the Christian principles of the Trussell Trust). A report by Eckley and Sefton (2015) for the Church Urban Fund suggests that 81 per cent of Church of England churches are involved with food banks. In this context, Allen (2016) has written critically on the importance attached to charitable giving (rather than social change) by privileged church voices, suggesting that food banks - as a response to poverty - are in keeping with the dominant Christian social tradition in Britain. Such an approach, he asserts, is focused on charity at the expense of 'fellowship' incorporating hospitality and sharing (though see the response of Pemberton (2019) on the potential of foodbank volunteering), while Shannahan (2019) argues for an ongoing consideration of the potential of liberation theology and poverty activism. Given the growth of faith-based food banks, the questions provoked by such 
Table 2 Actions and tasks comprising key social practices

\begin{tabular}{|c|c|c|}
\hline Actions/Tasks & Social Practices & Practice-arrangement bundle \\
\hline $\begin{array}{l}\text { Moving into an environment of } \\
\text { 'hardship'; Feeling and } \\
\text { expressing sympathy; Careful } \\
\text { listening; Reserving judgement; } \\
\text { Having empathy for 'rudeness'; } \\
\text { Acting as a Christian; Engaging } \\
\text { with other beliefs; Reflecting on } \\
\text { political anger }\end{array}$ & Helping others & $\begin{array}{l}\text { All three social practices are } \\
\text { performed, with changing } \\
\text { emphasis depending on the } \\
\text { on-going situation. The } \\
\text { breakdown of one social practice } \\
\text { has implications for the others } \\
\text { (they are 'meshed') and are } \\
\text { suffused by 'faith-based }\end{array}$ \\
\hline $\begin{array}{l}\text { Intervention by church; Prayer; } \\
\text { Making use of religious texts; } \\
\text { Compartmentalising emotions; } \\
\text { Taking breaks; Recognising } \\
\text { fatigue; Intervention by } \\
\text { managers; Working to } \\
\text { constraints }\end{array}$ & $\begin{array}{l}\text { Deploying coping } \\
\text { strategies }\end{array}$ & practices' $^{\prime}$ \\
\hline $\begin{array}{l}\text { Taking on different work roles; } \\
\text { Having freedom to innovate; } \\
\text { Asking how people are; Making } \\
\text { hot drinks; Having a laugh; } \\
\text { Identifying appropriate items; } \\
\text { Recognising the qualities of } \\
\text { managers; }\end{array}$ & $\begin{array}{l}\text { Creating } \\
\text { atmospheres }\end{array}$ & \\
\hline
\end{tabular}

analyses highlight the need to understand how faith features in the social practices of food bank voluntary work, including the potentially exclusionary effects of the dominance of Christian-based food aid (Power et al., 2017). Drawing on ethnographic studies in Finland, Salonen (2016) considers contestation between religious faith and secularism in 'food assistance places', suggesting that the active construction of space mediates the negotiation of religious practices. We agree with the proposal that such relational features of faith and place making are made through practices. In the following section we consider how social practices - suffused with faith-based practices - comprise the work of food bank volunteering.

\section{The social practices of food bank volunteering}

The following table details the three key social practices comprising the work of food bank volunteering (the practice-arrangement bundle). It shows the main actions/tasks making up the practice. Each social practice is discussed below.

\section{Helping others}

The social practice of 'helping others' encompassed a range of actions, from entering into food bank volunteer work to developing techniques for engagement such as careful listening. It is 
important to recognise the power imbalances and inequalities which exist between volunteers and people using the food bank (as critiqued by Poppendieck, 1998; Strong, 2021) when interpreting these social practices. Some participants discussed how church involvement had increased their awareness of food banks and social issues more generally:

Participant 04: ... I always felt I would like to do something that perhaps took me out of my comfort zone and meet people who really were having hardship. Because it's so easy to stay in your own environment and even in a church environment and not meet people like that at all.

In this passage, the participant discusses how involvement with the food bank was enabled by conversations in church (and through existing connections). They describe church members forming a relatively homogenous socio-economic group (as well as sharing religious views). There is also a recognition that (to slightly paraphrase) 'even a church environment' does not necessarily include people who use food banks. Such a recognition corresponds with the arguments of Allen (2016) about the privileged position occupied by church food bank volunteers and managers. This participant went on to discuss how her sympathies could vary depending upon people's situations:

Participant 04: Some you feel more sympathy for than others I have to say (laughs)... particularly I suppose the women who come in, the refugee women who come, often believing that they're going to get a whole new life, children with them and sometimes, they're stuck here in not very pleasant surroundings. I feel sometimes they must feel very let down.

In the above quote, the participant is expressing sympathy and compassion for people using the food bank, but also recognises that she finds some situations more affecting than others. For another participant, their approach to working with clients in difficult situations drew upon their faith:

Participant 10: I think I've learned to listen carefully... I think sometimes you're judgemental aren't you on people, not to be judgemental, try to put yourself into their situation you know and I try to be supportive. Yeah I think I have learned to be more understanding yeah, not judgemental. Compassionate perhaps.

This participant reflected on her religious belief and practice; that a Christian should support other people. However, she also recognises that she has developed her compassion through her active work in the food bank, including through being careful to listen to people's experiences. Her Christian beliefs give her a guide to how she should act, but putting those beliefs into practice then involves developing situational experience, which she recognises can be testing at times.

For another participant, in response to a question about support between volunteers, she invokes a sense of neighbourliness between all people in the food bank:

Participant 08: This is stupid. It's not stupid to me but it sounds stupid. As a Christian this is what the bible tells us to do. That we've got to help each other you know... Everybody's your neighbour... it doesn't matter what circumstances they come here in, I mean some of them come in here and wow, they're a bit whiffy. We can sort that out, if we've got toiletries we'll give them toiletries. 
Here the participant articulates corporeal points of difference between volunteers and people using the food bank. She points to the material resources they have in the food bank to address these differences (toiletries). Although driven by compassion, neighbourliness also involves helping people to become more like the volunteers. Another participant spoke in more missionary terms about the kind of active engagement to be undertaken:

Participant 03: There's not enough (clients) staying and I think that's a shame because the other manager said that's your job, the Christian side of it ... some don't want to know that, some just want to get their food and get out... I was talking to friends yesterday at church and they said oh that's such a shame...you're missing out, they're missing out on things. But of course a lot of them are foreign, they don't want to be Christians.

Here people using the food bank are characterised as missing out on important aspects of the food bank environment, but in quite different ways. There is an implied recognition that people might find the business of handing in a voucher and receiving their food difficult enough and don't want to stay (there is also the possibility that the conversation might turn to matters of faith). However, the participant also raises the issue of people having other forms of faith. Rather than considering this as a potential starting point for inter-faith discussions, the participant seems disappointed that there would be little opportunity for people to 'be Christians'.

The process of putting Christian values into action was a motivation for some participants:

Participant 06: I chose a community project because I wanted to see how you could, as a, you know as a church engage with a community project and put your Christian faith into action... This is what I want to be doing... Not stand up in a pulpit and spout every Sunday but actually to come in and work with people and do things.

For this participant (who was undertaking ecclesiastical training) there was a strong motivation to engage in a form of work requiring practical action, in a locality with many more pressing socio-economic problems than the parish she lived in. Having contact and interactions with people who were suffering seemed a particularly important factor and she had experience of the difficulties faced by people without UK citizenship (and who may have come to the UK to seek refuge, as described by Participant 04). A series of situations involving visa and benefit issues for clients leading to increased poverty had caused her to develop anger towards government institutions:

Participant 06: you reflect on that [changing visa rules] and also reflect on it from a theological point of view, but I got very incensed with the Home Office. I couldn't get past that cos I, that to me that's just wrong. But you could get to become a political activist...

Here a distinction is drawn between the work of the volunteers in the food bank and political activism. Her (political) anger at people becoming severely destitute seems to sit uncomfortably with the form of practical action she discussed previously. There is recognition that seeking to bring about change in people's conditions involves politics, broadly defined. Anger at these conditions was also expressed by participants who did not have involvement with organised religion: 
Participant 01: Do I get angry? I get furious. And I get really angry simply because we shouldn't have to do this. We really shouldn't... But any Labour government, it's not just Conservative, the Labour government started it, the policies are wrong, they are not investing, they don't have enough people, they also sanction at a moment's notice, so it's all very well that people get their Universal Credit sorted out, they do one thing wrong - bang, it's taken off them.

She articulates her exasperation at the very existence of food banks but struggles to place her anger beyond a general dismissal of successive governments (the one specific policy she does mention is Universal Credit). There are discernible differences in the way her fury remains unresolved, while Participant 06 explicitly tempers their anger through recourse to faith and implies that political activism is not within the role of a volunteer. Here faith suffuses the practice of helping others through 'acting as a Christian'. Shared routines and actions comprising a social practice - in this case 'Helping others' - are suffused with faith-based practices which produce variations within the practice. Variations within a social practice have been considered as 'basic features' of social practices, meaningfully constructed and elements of performance (Hui, 2017). The variation described above is one we will return to in the conclusion section, exemplifying as it does some salient considerations for 'spaces of encounter'.

\section{Deploying coping strategies}

Along with the practice of 'helping others', volunteers also shared a repertoire of actions to help them cope with their work. In their deployment of coping strategies, volunteers drew upon spiritual and non-spiritual reasoning and practice. For participants who expressed religious involvement, the practices of their Christian faith were important:

Participant 03: I told someone... that God had other ideas. Yes, our minister at our church asked me if I'd get up and say what I did at the food bank, the congregation, packed. And that's what I said, I said you see, I felt God had other ideas. He wanted me to do this.

Her faith, the church as an institution and the intervention of a senior cleric coalesced to act as a rationale for continuing to do something she found difficult. She had previously described her wellbeing as 'not too good' (and linked this to her hearing problems), but that she found working at the food bank therapeutic.

Despite some participants following a religious motivation to work in the food bank, there were times when they doubted it was something they wanted to continue doing. One participant described the importance of talking with other volunteers in order to share experiences, but also discussed the role of prayer in helping to address her doubts. Another identified the importance of prayer as a shared activity within this social practice:

Participant 08: Because the food bank has a Christian ethos, hence the prayers that I said ... but I insist that they're said each Tuesday because I think it starts the day and puts us all together.

The limits of religious faith and texts were also recognised:

Participant 06: I don't go home and read the bible cos the bible doesn't always help. But you can reflect on things and you can reflect on the fact that you can't solve the problems of all the world. 
From these quotes we can see how faith practices suffuse other social practices, with important variations. Participants can account for the limitations of their voluntary work through recourse to their faith, but may also reflect on the limitations of faith-based practices. As with 'Helping others', we will explore the implications of these practice variations in more detail in the Conclusions section.

As volunteers, participants were exposed to mentally demanding experiences. Those who worked 'front of house' described how they had learned to embed their emotions within the space of the food bank:

Participant 09: Mostly meet and greet, cups of tea, a chat erm. Initially I found it very gruelling, I did get really quite upset. So then the manager said you don't take this home with you, you've got to leave this here. So it took a while didn't it till I got used to that.

This regulation of interaction and emotions also involved reflecting and acting upon situations:

Participant 07: I mean certainly when the Syrians [refugees] first came, most days of the week we were doing things and it was fine cos it was time limited but... I've got other things going on... And different times of your life you can do stuff and other times you can't.

The volunteers recognised the need to remove themselves from difficult situations to achieve physical and emotional distance. Such breaks could involve taking a couple of minutes to weep, or staying away for a couple of weeks to replenish. Taking breaks was not simply an individual act, but was embedded within ongoing interactions with other volunteers and managers:

Participant 11: There was... there was one moment where I walked out... But then [the Manager] came and we talked it through ... there were too many clients and I felt so stretched so much across so many different things ... and it was just, I can't do all this. I'm not being paid for this, I can't do this.

In order to successfully maintain wellbeing, some volunteers spoke of the need to work within the constraints of their roles. This involved accepting that problems faced by people using the food bank were not necessarily something they could 'fix'.

\section{Creating atmospheres}

As elements of social practice, atmospheres have been described by Reckwitz (2012) drawing on Böhme (2000) - as affective moods which are integral parts of social practices produced within particular environments (or spatial arrangements). Such spatial arrangements are not simply buildings containing objects but following Schatzki (2005) are elements of practice-bundles with materials, competencies and meanings (Shove et al., 2012). For the volunteers, creating situated atmospheres involved balancing work roles, teams, actions and interactions with people using the food bank. The purpose of such atmospheres was to increase the opportunities for everyone to experience wellbeing, 
albeit if only temporarily. A key element of this was volunteers forming a collective (a 'team'), having 'camaraderie' and being able to use this to generate atmospheres.

Volunteers described being able to define and redefine their role in the food bank team and undertaking a diverse range of activities, including sorting donated food and clothes, preparing refreshments and meals, giving out food parcels to clients and listening and offering advice. Flexibility and an ambiguous role was felt to be important in generating a happy, working atmosphere and volunteers described positioning themselves on each shift:

Participant 10: Well I particularly enjoy being in the kitchen, working alongside other volunteers and actually I don't mind what I do... working as a team, that's the best aspect of it.

Participant 13: It's better in a way to have an ambiguous role because there's loads of people in the kitchen today, for example, but tomorrow you could just have two or three.

Participant 04: We like to feel that we're flexible and could do anything.

All these accounts relate to the interplay of spatial arrangements, interactions and tasks to be performed. As suggested previously, the connections between the social practices of 'Helping others' and 'Deploying coping strategies' comprise a tension for the volunteers between engaging with people using the food bank and becoming overwhelmed. Creating atmospheres has its own distinctive features as a social practice, but is also an outcome of these tensions. However, the volunteers are not simply creating atmospheres for themselves and their own wellbeing:

Participant 12: [I enjoy] the camaraderie really. We have a good laugh, we do. We have some fun as well and we try to make it fun for the clients when they come in.

Volunteers sought to generate atmospheres which they considered to be relaxed, safe, fun and enable people to talk and share stories. In order to do this they have organised their work activities around flexibility and through a knowledge of the people who come to use the food bank:

Participant 07: Remembering oh you've got a three year-old and a five year-old, right I've got just what you need. These trousers might fit your son and this dress is perfect.

Anderson (2009) has written that atmospheres emerge in collective situations as well as being felt by the individual; shifting from 'shared ground' to 'subjective states'. The volunteers assume a responsibility for creating atmospheres, but they cannot determine how atmospheres will form, emanate and be perceived and felt. This is the outcome of situated individual and shared talk and actions taking place in specific (and emerging) spatial and sensory contexts. Nevertheless, identifying the best fitting clothes for someone's son or daughter is not only an action focused on an end, but through remembrance, recognition and kindness activities are imbued with qualities intended to enrol people into a shared (yet subjective) state. Yet such actions can be problematised. Midgley (2018) has considered how care in food assistance spaces should be premised on on-going mutual 
recognition of people's capabilities. There is therefore a need to ensure kind actions do not reinforce a passive construction of vulnerabilities. As with the social practices of 'Helping others' and 'Deploying coping strategies', in the Discussion and Conclusion sections we further elaborate on the implications of these practices for 'spaces of encounter'.

Atmospheres are recognised by the volunteers as key elements of a social practice; further they emphasise the importance of atmospheres when verbal communication is difficult. Helping people who have been forced to leave their home countries (such as Syria) and who have endured traumatic experiences means being attentive to pace (a relaxed atmosphere), touch (a big hug for those who want one), humour (sharing laughter) and having useful objects (clothes, bicycles, food) present and made accessible. Further, laughter in particular has been analysed as more than humour, with 'events of laughter' having atmospheric affects with multiple and contingent manifestations (Emmerson, 2017). The importance of 'events of laughter' to the intersection of social practices is considered in the Discussion section.

Earlier in this article we discussed the suffusion of social practices by faith-based actions and have considered how the social practices of 'helping others' and 'deploying coping strategies' were formed by and responded to such suffusion. One participant (who spoke in missionary terms about her interactions with people using the food bank) described her disappointment that people might just '. .. get their food and get out.' Faith suffused social practices with a sense that the meaning of volunteer work had to be conceptualised in relation to Christianity, whether that meant invoking neighbourliness, questioning purpose or having a sceptical view of the practical import of religious texts. Social practices were not dominated by faith-based practices but were responsive to them.

\section{Discussion}

We began this article by discussing current critical perspectives on the growth of food banking in the UK, including those identifying opportunities for progressive action. The focus of our study was on understanding the social practices of food bank volunteer work. It has allowed us to develop a distinctive perspective on such 'spaces of encounter' (Williams et al., 2016) and 'ethical in-commonness' (Cloke et al., 2017), informed by social practice approaches. To recap, Williams et al. (2016) point to the potential for progressive politics in and though such spaces, suggesting that:

...there are significant opportunities for activist groups to collaborate with what might otherwise be thought of as 'unusual' suspects (religious 'publics' and charitable food providers) who are more usually seen as barriers to more radical approaches to a more socially just and ecologically sustainable food system.

Our analysis of the social practices of food bank volunteer work drew on the accounts of 'unusual' suspects and others. As stated in the Methods section, just over half of the volunteers (seven from thirteen) described themselves as taking part in organised religion (and were Christians). Two of the three research sites were operated by the Trussell Trust (one from a church). The other site also operated from a church. Although our entry point (in terms of research questions and topic guides) was through discussions of situated wellbeing (the notion of situated wellbeing became a methodological heuristic), our analysis of the data revealed three social practices to be constitutive of the work of 
volunteering: 'helping others', 'deploying coping strategies' and 'creating atmospheres'. These three forms of social practice were, we argue, 'suffused' by faith-based practice in different ways. As we discuss below, the way these practices were 'bundled', 'suffused' and contained 'variation' has important implications for spaces of encounter.

While not all volunteers were involved in organised religion, faith-based practices suffused the social practices of 'helping others', 'deploying coping strategies' and 'creating atmospheres', producing variations within the practices and the practice-bundle. In performing 'helping others', for some volunteers, faith-based practices provided a rationale for action and mediated responses to 'political' issues and actions. Practical action rather than performative discourse ('Not stand up in a pulpit and spout') was often favoured, in keeping with Cloke and Beaumont's (2013) notion of food banks as pragmatic and liminal sites of rapprochement of the secular and non-secular. Salonen (2016) describes differences between 'restorative' and 'accommodative' understandings of food assistance work, the former comprising public debate/empowerment (deemed non-religious) and conversion, forgiveness and hope (deemed religious). These variations and tensions within the social practice of 'Helping others' have implications for 'Spaces of encounter', as discussed further below.

In the practice of 'Deploying coping strategies', recourse to faith-based practices varied, with prayer recognised by some as an important means for coping, while others described how reading the bible was not part of their coping repertoire (signalling variation between individual and shared activities and the role of materials and meanings). More typical was the sharing of stress and sadness with other volunteers and with managers and co-ordinators, who could speak from their experiences or suggest a break from the immediate task and hand. One action within this practice - not taking things home with you - has some resemblance to the issues discussed under 'Helping others'. Specifically, in order to cope with the feelings and thoughts provoked by their work, volunteers were sometimes encouraged to compartmentalise their emotions and experiences. Such an approach to coping - combined with perceived limits to the extent of social and political critique and action - has implications for the development of 'public debate' and in developing politically-oriented discussion which might form part of a 'space of encounter'. The diverse arguments of Cloke et al. (2017), Allen (2016), Pemberton (2019) and Shannahan (2019) are relevant here in considering the form and parameters of public debate when social practices are suffused by faith-based practice. Shannahan (2019) argues that (religious) faith groups are well placed to challenge the political choices producing the structural violence of poverty. In a close reading of (and with) Gramsci, Slothuus (2021) has considered how a 'secular-political form of faith' - as collective affects - should be recognised as a core feature of social transformation (as distinct from 'rational', 'liberal' interventions). It is beyond the scope of this article to consider such proposals in detail, but the role of emotions, passions and faith (both secular and religious) in political debate merits further research in the context of food banks (see also Mouffe, 2005 on the weaknesses of Rawlsian liberal 'reasonable' pluralism). Food bank managers and co-ordinators can occupy an important role in setting the scope and form of such debate, including the critical discussion of the causes of poverty and the growth in food bank use.

It is important to restate that all three forms of social practice - 'Helping others', 'Deploying coping strategies' and 'Creating atmospheres - exist as a practice-arrangement bundle (Schatzki, 2005) forming the work of food bank volunteering. The social practices 
of 'helping others' and 'developing coping strategies' comprised the performance of shared actions and tasks which contribute to the nexus of which 'creating atmospheres' is part. The distinctiveness of 'creating atmospheres' as a social practice is in - following Shove et al. (2012) and Maller (2015) - the specific meanings (happiness in the work environment), competencies (knowing about the circumstances of families and individuals using the food bank) and materials (food items, clothes). The social practice of 'creating atmospheres' is embedded within the ongoing emergence of general and specific atmospheres. From a social practice perspective, Reckwitz (2017) has noted the experience of atmospheres emerges from social practices. Therefore, it is important to ask - how are people within a bundle of social practices (the volunteers in this case) experiencing atmospheres and what are the implications for those who are do not share the same membership of the practice? Trying to 'make things fun' for people using the food bank is as much about supporting atmospheres of 'camaraderie' for the volunteers. Variations identified in the practice of 'helping others' and 'deploying coping strategies' suggests that the suffusion of faith-based practice influences how the volunteers (as practitioners of the practices) interact with people using the foodbank.

The practice of 'creating atmospheres' has a distinctive role here, as intersections between social practices within and outwith the practice-bundle of the volunteers become possible (Shove et al., 2012; Maller, 2015; Hui, 2017). Specifically, 'events of laughter', discussion over the appropriateness of clothing for a child and the organisations of spaces within the food bank converge to produce performance of intersecting practices, and such configurations should be recognised and reflected upon if ethical in-commonness is to nurture solidarities. Importantly this should not marginalise the need for continuous critique of the existence of food banks. Recent campaigns - led by those involved in food bank provision - have sought to highlight the need for a multifaceted approach to addressing food poverty, rather than uncritically consolidating the growth in food bank use (for the 'Right to Food Campaign' on actions focused towards the elimination of food poverty, see Byrne et al., 2021).

\section{Conclusions}

In setting out these social practices forming food bank volunteer work, and their suffusion by faith-based practices, we have made mention of the role of managers and co-ordinators (though this was not our primary focus). As with our discussion of intersections between the practices of volunteers and people using food banks, intersections between volunteers and managers are also critical to the performance of practices, leading us to consider the social practices of organisations (Schatzki, 2005; Feldman and Orlikowski, 2011). A number of studies have analysed food bank and food assistance work from an organisational perspective (Santini and Cavicchi, 2014; Coque and González-Torre, 2017; Hebinck et al., 2018; lafrati, 2018). In considering tensions between demands and organisational ambitions (for example, between transactional and communal forms of interaction), one approach which draws on a social practice perspective - 'transformative social innovation' - has potential for future investigations (see Hebinck et al., 2018). It is not within the scope of this article to develop a detailed argument here, but our analysis of volunteers' social practices provides an important inroad to build on the four components ('shades of change') of transformative social innovations set out by Avelino et al. (2019): social innovation (new ways of doing, organising, knowing and framing); system 
innovation (changing institutions, social structures and infrastructures); game-changers (events, trends and developments that change the conditions for interactions); narratives of change (sets of ideas, concepts, metaphors). By understanding food bank volunteer work from a social practice perspective (and embedded in the growing literature on VCO's providing emergency food aid and food assistance), we can begin to build an analysis of organisations, focused on change through a longitudinal approach. Such analyses may provide an important lens for considering the implications of the growth and diversification of food banks and food assistance for social infrastructure and solidarities, during a time of crisis.

When considering limitations, the study could have drawn upon a broader demographic of volunteers - in particular, male volunteers. The sample size could have been expanded. However, thematic saturation (Saunders et al., 2018) was reached at the study sites. A greater diversity of study sites could have added new insights - in particular in relation to those with other or no faith - and this could be further explored in future studies. In particular such studies might seek to explore further how such team-working was established and maintained (or not), particularly in more diverse contexts. A relatively novel feature of our study was the focus on volunteers - rather than on the people who used food banks. However, the accounts of the participants draws attention to the severe poverty experienced by many people in parts of the UK (a situation, as suggested previously, well examined by sources cited in the introduction) and, of course, in other countries where food banks exist (with manifold implications for social policy and public health). Volunteers in food banks are engaging in an enterprise the existence of which should continue to be the focus of scrutiny and challenge.

\section{Acknowledgements}

The authors acknowledge the research participants; without their involvement the research would not have been possible. The views expressed here are those of the Authors and not necessarily those of Northumbria Healthcare NHS Foundation Trust or NHS Health Call. In order to respect the confidentiality of research participants, consent was not sought to make available original transcripts. Therefore the data cannot be made open.

\section{Note}

1 We would like to thank our three excellent reviewers for making very insightful comments and suggestions in this regard (and throughout).

\section{References}

Allen, C. (2016) 'Food poverty and christianity in Britain: a theological reassessment', Political Theology, $17,4,361-77$.

Anderson, B. (2009) 'Affective atmospheres', Emotion, Space and Society, 2, 2, 77-81.

Armour, S. and Barton, G. (2019) 'Exploring volunteering in a food bank and psychological wellbeing', Voluntary Sector Review, 10, 1, 39-57.

Avelino, F., Wittmayer, J. M., Pel, B., Weaver, P., Dumitru, A., Haxeltine, A., Kemp, R., Jørgense, M. S., Baule, T., Ruijsinkg, S. and O'Riordan, T. (2019) 'Transformative social innovation and (dis)empowerment', Technological Forecasting and Social Change, 145, 195-206. 
Baylis, F., Kenny, N. P. and Sherwin, S. (2008) 'A relational account of public health ethics', Public Health Ethics, 1, 3, 196-209.

Blue, S., Shove, E., Carmona, C. and Kelly, M. P. (2016) 'Theories of practice and public health: understanding (un)healthy practices', Critical Public Health, 26, 1, 36-50.

Böhme, G. (2000) Atmosphäre: Essays zur neuen Ästhetik, Frankfurt am Main: Suhrkamp.

Braun, V. and Clarke, V. (2006) 'Using thematic analysis in psychology', Qualitative Research in Psychology, 3, 2, 77-101.

Byrne, I., Chakrabarti, S., Chapman, J., Sinha, I. and Fans Supporting Foodbanks (2021) 'Delivering a right to food for the UK', https://www.ianbyrne.org/right-to-food [accessed 17.06.2021].

Caplan, P. (2016) 'Big society or broken society? Food banks in the UK', Anthropology Today, 32, 1, 5-9.

Carlisle, S., Henderson, G. and Hanlon, P. W. (2009) "Wellbeing': a collateral casualty of modernity?', Social Science and Medicine, 69, 1556-60.

Carson, E. A. (2014) 'Canadian food banks and the depoliticization of food insecurity at the individual and community Levels', Canadian Review of Social Policy, 70, 7-21.

Chiao, C. (2018) 'Beyond health care: volunteer work, social participation, and late-life general cognitive status in Taiwan', Social Science and Medicine, 229, 154-60.

Cloke, P. and Beaumont, J. (2013) 'Geographies of postsecular rapprochement in the city', Progress in Human Geography, 37, 1, 27-51.

Cloke, P., May, J. and Williams, A. (2017) 'The geographies of food banks in the meantime', Progress in Human Geography, 41, 6, 703-26.

Coque, J. and González-Torre, P. L. (2017) 'Adapting nonprofit resources to new social demands: the food banks in Spain', Sustainability, 9, 4, 643.

Deci, E. L. and Ryan, R. M. (2008) 'Hedonia, eudaimonia, and well-being: an introduction', Journal of Happiness Studies, 9, 1-11.

Dowler, E. and Lambie-Mumford, H. (2015) 'Introduction: hunger, food and social policy in austerity', Social Policy and Society, 14, 3, 411-15.

Eckley, B. and Sefton, T. (2015) 'Church in action: a national survey of church-based social action', The Church of England/Church Urban Fund, https://www.cuf.org.uk/assets/documents/Church-in-Action2015_0.pdf [accessed 13.01.2020].

Emmerson, P. (2017) 'Thinking laughter beyond humour: atmospheric refrains and ethical indeterminacies in spaces of care', Environment and Planning A, 49, 9, 2082-98.

Feldman, M. S. and Orlikowski, W. J. (2011) 'Theorizing practice and practicing theory', Organization Science, 22, 5, 1240-53.

Fisher, M. (2009) Capitalist Realism: Is There No Alternative?, Ropley: 0 Books.

Garthwaite, K. (2016) Hunger Pains: Life Inside Food Bank Britain, Bristol: Policy Press.

Garthwaite, K. (2017) "I feel I'm giving something back to society': constructing the 'active citizen' and responsibilising foodbank use', Social Policy and Society, 16, 2, 283-92.

Gilster, M. E. (2012) 'Comparing neighbourhood-focused activism and volunteerism: psychological well-being and social connectedness', Journal of Community Psychology, 40, 7, 769-84.

Hebinck, A., Galli, F., Sabrina Arcuri, S., Carroll, B., O'Connor, D. and Oostindie, H. (2018) 'Capturing change in European food assistance practices: a transformative social innovation perspective', Local Environment, 23, 4, 398-413.

Hitchings, R. (2012) 'People can talk about their practices', Area, 44, 1, 61-7.

Hui, A. (2017) 'Variations and the intersection of practices', in A. Hui, T. Schatzki and E. Shove (eds.), The Nexus of Practices: Connections, Constellations and Practitioners, Oxford and New York: Routledge, 52-67.

Hui, A., Schatzki, T. and Shove, E. (2017) 'Introduction', in A. Hui, T. Schatzki and E. Shove (eds.), The Nexus of Practices: Connections, Constellations and Practitioners, Oxford and New York: Routledge, $1-7$.

lafrati, S. (2018) "'We're not a bottomless pit": food banks' capacity to sustainably meet increasing demand', Voluntary Sector Review, 9, 1, 39-53. 
Jang, H., Gonzales, E., Lee, Y. S. and Morrow-Howell, N. (2018) 'Formal volunteering as a protector of health in the context of social losses', Journal of Gerontological Social Work, 61, 8, 834-48.

Jenkinson, C. E., Dickens, A. P., Jones, K., Thompson-Coon, J., Taylor, R. S., Rogers, M., Bambra, C. L., Lang, I. and Richards, S. H. (2013) 'Is volunteering a public health intervention? A systematic review and meta-analysis of the health and survival of volunteers', BMC Public Health, 13, 773.

Keane, H., Weier, M., Fraser, D. and Gartner, C. (2017) "Anytime, anywhere': vaping as social practice', Critical Public Health, 27, 4, 465-76.

Lambie-Mumford, H. (2019) 'The growth of food banks in Britain and what they mean for social policy', Critical Social Policy, 39, 1, 3-22.

Lim, C. and MacGregor, C. A. (2014) 'Religion and volunteering in context: disentangling the contextual effects of religion on voluntary behavior', American Sociological Review, 77, 5, 747-79.

Loopstra, R. (2018) 'Rising food bank use in the UK: sign of a new public health emergency?', Nutrition Bulletin, 43, 1, 53-60.

MacLeod, M. A., Curl, A. and Kearns, A. (2019) 'Understanding the prevalence and drivers of food bank use: evidence from deprived communities in Glasgow', Social Policy and Society, 18, 1, 67-86.

Maller, C. J. (2015) 'Understanding health through social practices: performance and materiality in everyday life', Sociology of Health and IIIness, 37, 1, 52-66.

May, J., Williams, A., Cloke, P. and Cherry, L. (2019) 'Food banks and the production of scarcity', Transactions of the Institute of British Geographers, 45, 1, 1-15.

Meah, A. (2014) 'Still blaming the consumer? Geographies of responsibility in domestic food safety practices', Critical Public Health, 24, 1, 88-103.

Mencken, F. C. and Fitz, B. (2013) 'Image of God and community volunteering among religious adherents in the United States', Review of Religious Research, 55, 3, 491-508.

Midgley, J. (2018) 'You were a lifesaver': encountering the potentials of vulnerability and self-care in a community café', Ethics and Social Welfare, 12, 1, 49-64.

Milne, R. (2011) 'A focus group study of food safety practices in relation to listeriosis among the over-60s', Critical Public Health, 21, 4, 485-95

Mouffe, C. (2005) 'The limits of John Rawls's pluralism', Politics, Philosophy and Economics, 4, 2, $221-31$.

Nicolini, D. (2012) Practice Theory, Work, and Organization: An Introduction, Oxford: Oxford University Press.

Okun, M. A., August, K. J., Rook, K. S. and Newsom, J. T. (2010) 'Does volunteering moderate the relation between functional limitations and mortality?', Social Science and Medicine, 71, 1662-8.

Pemberton, C. S. C. (2019) 'Between ecclesiology and ontology: a response to Chris Allen on British food banks', Political Theology, 20, 1, 85-101.

Poppendieck, J. (1998) Sweet Charity? Emergency Food and the End of Entitlement, New York and London: Viking Penguin/Penguin Books.

Power, M. S., Small, N., Doherty, B., Stewart-Knox, B. and Pickett, K. E. (2017) "Bringing heaven down to earth": the purpose and place of religion in UK food aid', Social Enterprise Journal, 13, 3, 251-67.

Power, M., Doherty, B., Pybus, K. and Pickett, K. (2020) 'How COVID-19 has exposed inequalities in the UK food system: the case of UK food and poverty', Emerald Open Research, 2, 11.

Reckwitz, A. (2002) 'Toward a theory of social practices: a development in culturalist theorizing', European Journal of Social Theory, 5, 2, 243-63.

Reckwitz, A. (2012) 'Affective spaces: a praxeological outlook', Rethinking History: The Journal of Theory and Practice, 16, 2, 241-58.

Reckwitz, A. (2017) 'Practices and their affects', in A. Hui, T. Schatzki and E. Shove (eds.), The Nexus of Practices: Connections, Constellations and Practitioners, Oxford and New York: Routledge, 114-25.

Roche, A. and Ogden, J. (2016) 'Predictors of burnout and health status in Samaritans' listening volunteers', Psychology, Health and Medicine, 22, 10, 1169-74.

Salonen, A. S. (2016) 'Locating religion in the context of charitable food assistance: an ethnographic study of food banks in a Finnish city', Journal of Contemporary Religion, 31, 1, 35-50. 
Santini, C. and Cavicchi, A. (2014) 'The adaptive change of the Italian Food Bank foundation: a case study', British Food Journal, 116, 9, 1446-59.

Saunders, B., Sim, J., Kingstone, T., Baker, S., Waterfield, J., Bartlam, B., Burroughs, H. and Jinks, C. (2018) 'Saturation in qualitative research: exploring its conceptualization and operationalization', Quality and Quantity, 52, 4, 1893-1907.

Schatzki, T. R. (2001) 'Practice mind-ed orders', in T. R. Schatzki, K. K. Cetina and E. von Savigny (eds.), The Practice Turn in Contemporary Theory, London and New York: Routledge, 42-55.

Schatzki, T. R. (2005) 'Peripheral vision: the sites of organisations', Organisation Studies, 26, 3, 465-84.

Schatzki, T. R. (2017) 'Sayings, texts and discursive formations', in A. Hui, T. Schatzki and E. Shove (eds.), The Nexus of Practices: Connections, Constellations and Practitioners, Oxford and New York: Routledge, $126-40$.

Shannahan, C. (2019) 'The violence of poverty: theology and activism in an "Age of Austerity"', Political Theology, 20, 3, 243-61.

Shove, E., Pantzar, M. and Watson, M. (2012) The Dynamics of Social Practice: Everyday Life and How It Changes, London: Sage.

Silverman, D. (2014) Interpreting Qualitative Data, 5th edn, London: Sage.

Slothuus, L. (2021) 'Faith between reason and affect: thinking with Antonio Gramsci', Distinktion: Journal of Social Theory, doi: https://doi.org/10.1080/1600910X.2021.1934505.

Smith, T. S. J. and Reid, L. (2018) 'Which 'being' in wellbeing? Ontology, wellness and the geographies of happiness', Progress in Human Geography, 42, 6, 807-29.

Sointu, E. (2005) 'The rise of an ideal: tracing changing discourses of wellbeing', Sociological Review, $53,2,255-74$.

Son, J. and Wilson, J. (2012) 'Volunteer work and hedonic, eudemonic, and social well-being', Sociological Forum, 27, 3, 658-81.

Strong, S. (2021) Facing hunger, framing food banks, imaging austerity, Social and Cultural Geography, doi: https://doi.org/10.1080/14649365.2021.1921247.

The Trussell Trust (2017) 'Foodbank demand soars across the UK', https://www.trusselltrust.org/2017/11/ 07/foodbank-demand-soars-across-uk/ [accessed: 20.02.2018].

Watson, M. (2013) 'Practices', in P. Jackson and the CONANX Group (eds.), Food Words: Essays in Culinary Culture, London: Berg, 157-60.

White, S. C. (2017) 'Relational wellbeing: re-centring the politics of happiness, policy and the self', Policy and Politics, 45, 2, 121-36.

Williams, A., Cloke, P., May, J. and Goodwin, M. (2016) 'Contested space: the contradictory political dynamics of food banking in the UK', Environment and Planning A, 48, 11, 2291-316.

Wilson, J. and Janoski, T. (1995) 'The contribution of religion to volunteer work', Sociology of Religion, $56,2,137-52$. 